\title{
Immunosuppressive agents are associated with peptic ulcer bleeding
}

\author{
MINORU TOMIZAWA ${ }^{1}$, FUMINOBU SHINOZAKI ${ }^{2}$, RUMIKO HASEGAWA ${ }^{3}$, \\ YOSHINORI SHIRAI ${ }^{3}$, YASUFUMI MOTOYOSHI ${ }^{4}$, TAKAO SUGIYAMA ${ }^{5}$, \\ SHIGENORI YAMAMOTO ${ }^{6}$ and NAOKI ISHIGE ${ }^{7}$
}

\author{
Departments of ${ }^{1}$ Gastroenterology, ${ }^{2}$ Radiology, ${ }^{3}$ Surgery, ${ }^{4}$ Neurology, ${ }^{5}$ Rheumatology, ${ }^{6}$ Pediatrics, \\ and ${ }^{7}$ Neurosurgery, National Hospital Organization Shimoshizu Hospital, Yotsukaido, Chiba 284-0003, Japan
}

Received January 6, 2016; Accepted January 6, 2017

DOI: $10.3892 / \mathrm{etm} .2017 .4214$

\begin{abstract}
Peptic ulcer bleeding can be fatal. Non-steroidal anti-inflammatory drugs (NSAIDs), corticosteroids and immunosuppressive agents are administered for long-term usage. The present study assessed the association between peptic ulcer bleeding and administration of NSAIDs, corticosteroids and immunosuppressive agents. Furthermore, the efficacy of lowering the risk of peptic ulcer bleeding with proton pump inhibitors (PPI) and histamine 2 receptor antagonists (H2RA) was evaluated. Medical records were retrospectively analyzed for patients subjected to an upper gastrointestinal (GI) endoscopy performed at the National Hospital Organization Shimoshizu Hospital (Yotsukaido, Japan) from October 2014 to September 2015. During this period, a total of 1,023 patients underwent an upper GI endoscopy. A total of 1,023 patients, including 431 males (age, 68.1 \pm 12.9 years) and 592 females (age, $66.4 \pm 12.3$ years), who had been administered NSAIDs, corticosteroids, immunosuppressive agents, PPIs and H2RAs, were respectively enrolled. Endoscopic findings of the patients were reviewed and their data were statistically analyzed. Logistic regression analysis was used to determine the odds ratio of peptic ulcer bleeding for each medication; immunosuppressive agents had an odds ratio of 5.83, which was larger than that for NSAIDs (4.77). The Wald test was applied to confirm the correlation between immunosuppressive agents and peptic ulcer bleeding. Furthermore, $\chi^{2}$ tests were applied to the correlation between peptic ulcer bleeding and administration of PPIs or H2RAs. Immunosuppressive agents had the largest $\chi^{2}$, and the P-value was 0.03 . Administration of PPIs was significantly correlated with non-peptic ulcer bleeding
\end{abstract}

Correspondence to: Dr Minoru Tomizawa, Department of Gastroenterology, National Hospital Organization Shimoshizu Hospital, 934-5 Shikawatashi, Yotsukaido, Chiba 284-0003, Japan E-mail: nihminor-cib@umin.ac.jp

Key words: nonsteroidal anti-inflammatory drugs, corticosteroids, immunosuppressive agents, proton pump inhibitor, histamine type 2 receptor antagonists, logistic regression analysis, Wald test
$(\mathrm{P}=0.02)$; furthermore, a tendency toward non-peptic ulcer bleeding with administration of H2RA was indicated, but it was not statistically significant $(\mathrm{P}=0.12)$. In conclusion, immunosuppressive agents were correlated with peptic ulcer bleeding and PPIs were effective at lowering the risk of peptic ulcer bleeding.

\section{Introduction}

Peptic ulcers comprise gastric and duodenal ulcers. Complications of peptic ulcers include bleeding, perforation and obstruction (1). Bleeding is a major problem of peptic ulcers, as it is at times fatal (2). Peptic ulcer bleeding is diagnosed and treated by upper gastrointestinal (GI) endoscopy (3). Known causes of peptic ulcer bleeding are the long-term administration of non-steroidal anti-inflammatory drugs (NSAIDs), anti-platelet agents, anti-coagulants and infection with Helicobacter pylori (4).

NSAIDs are commonly used for rheumatic diseases and persistent pain due to orthopedic diseases $(5,6)$. Rheumatic diseases have an autoimmune basis and affect connective tissue $(6,7)$. This inflammation damages tissue and impairs the patient's quality of life $(8,9)$. To suppress the autoimmune basis of the disease, corticosteroids and immunosuppressive agents are used (10-12). Tumor necrosis factor a blockers, biological modifiers, are also used to suppress the autoimmune response $(13,14)$. It is well known that corticosteroids trigger peptic ulcer bleeding by making the gastric mucosa susceptible to ulceration by gastric acid (15-17). However, the correlation between immunosuppressive agents and upper GI bleeding has remained to be determined.

For the prevention of peptic ulcer bleeding, proton pump inhibitors (PPIs) and histamine 2 receptor antagonists (H2RAs) are used (18). PPIs and H2RAs increase the $\mathrm{pH}$ of gastric acid, prevent damage of the gastric mucosa and promote the healing of peptic ulcers $(19,20)$. PPIs are superior to H2RAs in preventing peptic ulcer bleeding due to stress in patients in intensive care (21). However, the efficacy of the prevention of peptic ulcer bleeding has remained elusive in patients with long-term administration of PPIs or H2RAs.

In the present study, the association between peptic ulcer bleeding and administration of NSAIDs, corticosteroids and 
immunosuppressive agents was analyzed in patients with rheumatic or orthopedic diseases. Furthermore, the prevention of peptic ulcer bleeding by PPIs and H2RAs was evaluated.

\section{Materials and methods}

Ethics statement. The present study was approved by the National Hospital Organization Shimoshizu Hospital Ethics Committee (Yotsukaido, Japan). It was not considered a clinical trial, as the procedures were performed as part of a routine clinical practice. Written informed consent for inclusion in the study was waived. Patient records were anonymized and retrospectively analyzed. Written informed consent was obtained from all patients who were subjected to upper GI endoscopy.

Patients. Medical records were retrospectively analyzed for patients subjected to upper GI endoscopy performed at the National Hospital Organization Shimoshizu Hospital (Yotsukaido, Japan) from October 2014 to September 2015. During this period, a total of 1,023 patients underwent an upper GI endoscopy for the investigation of anemia, abdominal pain or tarry stool. In addition, certain patients underwent upper GI endoscopy for screening. The cohort comprised 431 males (age, 68.1 \pm 12.9 years) and 592 females (age, $66.4 \pm 12.3$ years).

Study design. The 1,023 patents were analyzed with regard to administration of NSAIDs, corticosteroids, immunosuppressive agents, PPIs and H2RAs. Endoscopic findings were reviewed in the 1,023 patients; these data were analyzed statistically. For patients with bleeding from peptic ulcers, results of urea breath test and past history of peptic ulcers were reviewed. The urea breath test was performed to detect Helicobacter pylori infection and outsourced to LSI Medience Corp. (Tokyo, Japan).

Medication. The cohort of the present study had received immunosuppressive agents, including methotrexate and tacrolimus, as well as biological agents, including infliximab, etanercept, adalimumab and golimumab. Corticosteroids and immunosuppressive agents were used for rheumatic diseases, such as rheumatoid arthritis and systemic lupus erythematosus. NSAIDs were administered to patients with lumbar discopathy and deformation spondylosis. Table I shows the number and ratio of patients administered each type of drug.

Upper GI endoscopy. Patients were subjected to upper GI endoscopy for screening, or investigation of abdominal symptoms or anemia. The endoscopic devices used were the GIF-N260H, GIF-XP260NS, GIF-PG260, GIF-XQ260 and GIF-Q260 (Olympus, Tokyo, Japan). A gastric or duodenal ulcer was considered to be a peptic ulcer. Bleeding from a peptic ulcer was restricted to a spurting vessel, an oozing vessel, a visible vessel or a clot, according to the Forrest classification system (22). Table II shows the diagnosis of patients with peptic ulcer bleeding. Seventeen and two patients were diagnosed with bleeding from gastric and duodenal ulcers, respectively.

Statistical analysis. Logistic regression analysis was used to determine the odds ratio and $95 \%$ confidence interval of peptic ulcer bleeding for each medication. The Wald test was
Table I. Number of patients taking each medication.

\begin{tabular}{lcr}
\hline Medication & Number of patients & Ratio, \% \\
\hline NSAIDs & 19 & 1.85 \\
Corticosteroids & 92 & 8.99 \\
Immunosuppressive agents & 30 & 2.93 \\
PPI & 118 & 10.51 \\
H2RA & 30 & 2.93 \\
\hline
\end{tabular}

NSAIDs, nonsteroidal anti-inflammatory drugs; PPI, proton pump inhibitor; H2RA, histamine type 2 receptor antagonist.

Table II. Diagnosis of upper gastrointestinal bleeding from peptic ulcers by endoscopy.

Peptic ulcer or

non-peptic ulcer

Number of

Peptic ulcer

Diagnosis

patients

Gastric ulcer

17

Duodenal ulcer

2

Total

19

applied to analyze the statistical significance of the correlation of peptic ulcer bleeding and medication (23). Chi-square tests were applied to analyze the correlation between peptic ulcer bleeding and administration of PPIs or H2RAs. P $<0.05$ was considered to indicate a statistically significant difference. JMP 10.0.2 software (SAS Institute, Cary, CA, USA) was used for statistical analysis.

\section{Results}

Patient characteristics. Table III shows the characteristics of patients with bleeding from peptic ulcers. The patients had been subjected to monotreatment with NSAIDs, immunosuppressive agents or corticosteroid, but not their combination. Four patients were subjected to the urea breath test, one of which was positive and had a history of peptic ulcer.

Effect of the medication with regard to bleeding. To calculate the odds ratios for various medication types with regard to peptic ulcer bleeding, logistic regression analysis was used (Table IV). The odds ratio of immunosuppressive agents was 5.83, which was larger than that of NSAID (4.77). It was found that among the different medications, immunosuppressive agents had the strongest correlation with peptic ulcer bleeding.

Confirmation of the association between medication and bleeding. To confirm the association between immunosuppressive agents and peptic ulcer bleeding, the Wald test was applied (Table V). Immunosuppressive agents had the largest $\chi^{2}$ result (4.98) and $\mathrm{P}=0.03$ (Table $\mathrm{V}$ ).

Proton-pump inhibitor and bleeding. To reveal the correlation between PPIs and peptic ulcer bleeding, a $\chi^{2}$ test was 
Table III. Characteristics of patients with bleeding from peptic ulcers.

\begin{tabular}{|c|c|c|c|c|c|c|c|c|c|}
\hline Patient no. & Diagnosis & Gender & Age & Disease & NSAIDs & $\begin{array}{c}\text { Immunosuppressive } \\
\text { agents }\end{array}$ & Corticosteroids & $\begin{array}{c}\text { History of } \\
\text { peptic ulcers }\end{array}$ & H.pylori \\
\hline 1 & GU & $\mathrm{F}$ & 79 & $\begin{array}{l}\text { Lumbar } \\
\text { discopathy }\end{array}$ & $(+)$ & $(-)$ & $(-)$ & $(-)$ & NA \\
\hline 2 & GU & M & 73 & RA & $(-)$ & $(-)$ & $(+)$ & $(-)$ & NA \\
\hline 3 & GU & M & 73 & RA & $(-)$ & $(-)$ & $(+)$ & $(-)$ & NA \\
\hline 4 & GU & M & 73 & RA & $(-)$ & $(-)$ & $(+)$ & $(-)$ & NA \\
\hline 5 & GU & $\mathrm{F}$ & 66 & $(-)$ & $(-)$ & $(+)$ & $(-)$ & $(-)$ & NA \\
\hline 6 & GU & $\mathrm{F}$ & 67 & RA & $(-)$ & $(+)$ & $(-)$ & $(-)$ & NA \\
\hline 7 & GU & M & 22 & DMD & $(-)$ & $(-)$ & $(-)$ & $(-)$ & NA \\
\hline 8 & GU & M & 78 & $(-)$ & $(-)$ & $(-)$ & $(-)$ & $(-)$ & NA \\
\hline 9 & GU & M & 72 & $(-)$ & $(-)$ & $(-)$ & $(-)$ & $(+)$ & NA \\
\hline 10 & GU & $\mathrm{M}$ & 72 & $(-)$ & $(-)$ & $(-)$ & $(-)$ & $(+)$ & NA \\
\hline 11 & $\mathrm{GU}$ & $\mathrm{M}$ & 84 & $(-)$ & $(-)$ & $(-)$ & $(-)$ & $(-)$ & NA \\
\hline 12 & $\mathrm{GU}$ & M & 71 & $(-)$ & $(-)$ & $(-)$ & $(-)$ & $(-)$ & NA \\
\hline 13 & $\mathrm{GU}$ & $\mathrm{F}$ & 70 & $(-)$ & $(-)$ & $(-)$ & $(-)$ & $(-)$ & NA \\
\hline 14 & $\mathrm{GU}$ & $\mathrm{M}$ & 69 & $(-)$ & $(-)$ & $(-)$ & $(-)$ & $(+)$ & $(+)$ \\
\hline 15 & $\mathrm{GU}$ & $\mathrm{F}$ & 84 & $(-)$ & $(-)$ & $(-)$ & $(-)$ & $(-)$ & NA \\
\hline 16 & $\mathrm{GU}$ & $\mathrm{F}$ & 87 & $(-)$ & $(-)$ & $(-)$ & $(-)$ & $(-)$ & NA \\
\hline 17 & $\mathrm{GU}$ & $\mathrm{F}$ & 70 & $(-)$ & $(-)$ & $(-)$ & $(-)$ & $(-)$ & $(+)$ \\
\hline 18 & DG & $\mathrm{F}$ & 42 & $(-)$ & $(-)$ & $(-)$ & $(-)$ & $(-)$ & $(-)$ \\
\hline 19 & DG & $\mathrm{F}$ & 42 & $(-)$ & $(-)$ & $(-)$ & $(-)$ & $(-)$ & $(-)$ \\
\hline
\end{tabular}

NSAIDs, non-steroidal anti-inflammatory drugs; GU, gastric ulcer; DG, duodenal ulcer; M, male; F, female; RA, rheumatoid arthritis; DMD, Duchenne muscular dystrophy; NA, not analyzed; H. pylori, Helicobacter pylori.

Table IV. Logistic regression analysis of the relationship between medication and bleeding from peptic ulcers.

\begin{tabular}{lcl}
\hline Medication & Odds ratio & $95 \%$ CI \\
\hline NSAIDs & 4.77 & $0.25-26.88$ \\
Corticosteroids & 2.77 & $0.62-9.09$ \\
Immunosuppressive agents & 5.83 & $0.88-22.96$ \\
\hline
\end{tabular}

CI,confidenceinterval,NSAIDs, nonsteroidal anti-inflammatorydrugs.

Table V. Wald test of the association between medication and bleeding from peptic ulcers.

\begin{tabular}{lcc}
\hline Medication & $\chi^{2}$ & P-value \\
\hline NSAIDs & 2.12 & 0.15 \\
Corticosteroids & 2.37 & 0.12 \\
Immunosuppressive agents & 4.98 & 0.03 \\
\hline
\end{tabular}

NSAIDs, non-steroidal anti-inflammatory drugs.

applied (Table VI). Administration of PPIs was significantly correlated with non-peptic ulcer bleeding $(\mathrm{P}=0.02)$.
Table VI. Correlation between PPI intake and bleeding from peptic ulcers.

\begin{tabular}{lccc}
\hline & \multicolumn{2}{c}{ Peptic ulcer bleeding $(\mathrm{P}=0.02)$} & \\
\cline { 2 - 3 } PPI intake & Negative, n (\%) & Positive, n (\%) & Total \\
\hline Yes & $892(87.19)$ & $13(1.27)$ & $905(88.47 \%)$ \\
No & $112(10.95)$ & $6(0.59)$ & $118(11.53 \%)$ \\
Total & $1,004(98.14)$ & $19(1.86)$ & $1,023(100 \%)$ \\
\hline
\end{tabular}

PPI, proton pump inhibitor. $\mathrm{P}=0.02$ compares $\mathrm{PPI}$ intake and no PPI treatment in peptic ulcer bleeding.

Histamine type 2 receptor antagonist and bleeding. To analyze the correlation between H2RAs and peptic ulcer bleeding, a $\chi^{2}$ test was applied (Table VII). A tendency toward non-peptic ulcer bleeding with administration of H2Ras was identified; however, it was not statistically significant $(\mathrm{P}=0.12)$.

\section{Discussion}

Case reports and case series have documented the use of immunosuppressive agents to treat patients with peptic ulcers (24-26). However, studies assessing the possible association between the administration of immunosuppressive agents 
Table VII. Correlation between H2RA intake and bleeding from peptic ulcers.

$$
\text { Peptic ulcer bleeding }(\mathrm{P}=0.12)
$$

H2RA intake Negative, n (\%) Positive, n (\%)

Total

\begin{tabular}{lccc}
\hline Yes & $976(95.41)$ & $17(1.66)$ & $993(97.07 \%)$ \\
No & $28(2.73)$ & $2(0.2)$ & $30(2.93 \%)$ \\
Total & $1004(98.14)$ & $19(1.86)$ & $1023(100 \%)$ \\
\hline
\end{tabular}

$\mathrm{H} 2 \mathrm{RA}$, histamine $\mathrm{H} 2$ receptor antagonist. $\mathrm{P}=0.12$ compares $\mathrm{H} 2 \mathrm{RA}$ intake and no H2RA treatment in peptic ulcer bleeding.

and peptic ulcer bleeding are currently lacking. To answer this question, the present case findings provided novel evidence that immunosuppressive agent use is significantly correlated with peptic ulcer bleeding. Although the mechanisms by which immunosuppressive agent use may be correlated with peptic ulcer bleeding is elusive, it is possible that these agents cause bleeding by inhibiting ulcer healing (26). The results of the present study are clinically important, as they are relevant to ensuring patient safety, with peptic ulcer bleeding being one reason for the discontinuation of immunosuppressive agents (27). Further studies with additional patients are therefore warranted to confirm these results.

NSAIDs and corticosteroids cause gastric and duodenal ulcers, and increase the risk of upper GI bleeding. In previous studies, NSAIDs and corticosteroids were rated to not pose any risk for peptic ulcer bleeding $(28,29)$. In the present study, NSAIDs and corticosteroids showed no correlation with upper GI bleeding. The results of the present study are therefore consistent with those of previous ones. However, it is premature to conclude that NSAIDs and corticosteroids are less hazardous. One reason is that in the present study, the number of patients treated with NSAIDs and corticosteroids was relatively small. Peptic ulcer bleeding is still fatal in certain patients, such as the elderly (30). Precautions should be taken for patients treated with NSAIDs and/or corticosteroids to avoid upper GI bleeding.

PPIs are effective for reducing peptic ulcer bleeding (31). They are more effective at lowering the risk of upper GI peptic ulcer bleeding than H2RAs (32). In the present study, PPIs significantly lowered the risk of peptic ulcer bleeding. Therefore, the results of the present study were consistent with those of previous ones. PPIs are frequently used in combination with NSAIDs or corticosteroids to lower the risk of peptic ulcer bleeding $(10,33)$. Likewise, PPIs may lower the risk of peptic ulcer bleeding associated with immunosuppressive agents. However, PPIs represent a risk factor for bleeding from the small intestine, hip fracture and cardiac events $(34,35)$. It is therefore recommended that long-term use of PPIs is avoided (36). With this regard, H2RAs may be recommended for long-term administration to prevent peptic ulcer bleeding.

A major limitation is that the present study was based on a relatively small number of patients. This may explain why no correlation was found between NSAIDs, corticosteroids, immunosuppressive agents and upper GI bleeding. In future studies, a larger number of patients should be enrolled and studied.

In conclusion, the present study revealed that immunosuppressive agents were correlated with peptic ulcer bleeding. However, PPIs were effective at lowering the risk of peptic ulcer bleeding.

\section{References}

1. Milosavljevic T, Kostić-Milosavljević M, Jovanović I and Krstić M: Complications of peptic ulcer disease. Dig Dis 29: 491-493, 2011.

2. Leontiadis GI, Molloy-Bland M, Moayyedi P and Howden CW: Effect of comorbidity on mortality in patients with peptic ulcer bleeding: Systematic review and meta-analysis. Am J Gastroenterol 108: 331-345; quiz 346, 2013.

3. Kim SY, Hyun JJ, Jung SW and Lee SW: Management of non-variceal upper gastrointestinal bleeding. Clin Endosc 45: 220-223, 2012.

4. Huang TC and Lee CL: Diagnosis, treatment, and outcome in patients with bleeding peptic ulcers and Helicobacter pylori infections. Biomed Res Int 2014: 658108, 2014.

5. Makris UE, Abrams RC, Gurland B and Reid MC: Management of persistent pain in the older patient: A clinical review. JAMA 312: 825-836, 2014.

6. Bahadur S, Keshri L and Pathak K: Adverse drug reactions and safety considerations of NSAIDs: Clinical analysis. Curr Drug Saf 6: 310-317, 2011.

7. Grateau G, Hentgen V, Stojanovic KS, Jéru I, Amselem S and Steichen O: How should we approach classification of autoinflammatory diseases? Nat Rev Rheumatol 9: 624-629, 2013.

8. da Mota LM, Laurindo IM and dos Santos Neto LL: Prospective evaluation of the quality of life in a cohort of patients with early rheumatoid arthritis. Rev Bras Reumatol 50: 249-261, 2010 (In English, Portuguese).

9. Radner H, Yoshida K, Mjaavatten MD, Aletaha D, Frits M, Lu B, Iannaccone C, Shadick N, Weinblatt M, Hmamouchi I, et al: Development of a multimorbidity index: Impact on quality of life using a rheumatoid arthritis cohort. Semin Arthritis Rheum 45: 167-173, 2015.

10. van der Goes MC, Jacobs JW and Bijlsma JW: The value of glucocorticoid co-therapy in different rheumatic diseases-positive and adverse effects. Arthritis Res Ther 16 (Suppl 2): S2, 2014.

11. Goodman SM, Cronstein BN and Bykerk VP: Outcomes related to methotrexate dose and route of administration in patients with rheumatoid arthritis: A systematic literature review. Clin Exp Rheumatol 33: 272-278, 2015.

12. Motomura H, Matsushita I, Seki E, Mine H and Kimura T: Inhibitory effect of tacrolimus on progression of joint damage in patients with rheumatoid arthritis. Int J Rheum Dis 17: 749-754, 2014.

13. Mok CC: Rituximab for the treatment of rheumatoid arthritis: An update. Drug Des Devel Ther 8: 87-100, 2014.

14. Tanaka Y and Hirata S: Intensive intervention can lead to a treatment holiday from biological DMARDs in patients with rheumatoid arthritis. Drugs 74: 2129-2139, 2014.

15. Gralnek IM, Dumonceau JM, Kuipers EJ, Lanas A, Sanders DS, Kurien M, Rotondano G, Hucl T, Dinis-Ribeiro M, Marmo R, et al: Diagnosis and management of nonvariceal upper gastrointestinal hemorrhage: European society of gastrointestinal endoscopy (ESGE) guideline. Endoscopy 47: a1-a46, 2015.

16. Niv Y, Boltin D, Halpern M, Cohen M, Levi Z, Vilkin A, Morgenstern S, Manugian V, St Lawrence E, Gagneux P, et al: Membrane-bound mucins and mucin terminal glycans expression in idiopathic or Helicobacter pylori, NSAID associated peptic ulcers. World J Gastroenterol 20: 14913-14920, 2014.

17. Bandyopadhyay U, Biswas K, Bandyopadhyay D, Ganguly CK and Banerjee RK: Dexamethasone makes the gastric mucosa susceptible to ulceration by inhibiting prostaglandin synthetase and peroxidase-two important gastroprotective enzymes. Mol Cell Biochem 202: 31-36, 1999.

18. Nakashima S, Ota S, Arai S, Yoshino K, Inao M, Ishikawa K, Nakayama N, Imai Y, Nagoshi S and Mochida S: Usefulness of anti-ulcer drugs for the prevention and treatment of peptic ulcers induced by low doses of aspirin. World J Gastroenterol 15: 727-731, 2009. 
19. Kyaw MH and Chan FK: Pharmacologic options in the management of upper gastrointestinal bleeding: Focus on the elderly. Drugs Aging 31: 349-361, 2014.

20. Tuskey A and Peura D: The use of $\mathrm{H} 2$ antagonists in treating and preventing NSAID-induced mucosal damage. Arthritis Res Ther 15 (Suppl 3): S6, 2013.

21. Alhazzani W, Alenezi F, Jaeschke RZ, Moayyedi P and Cook DJ: Proton pump inhibitors versus histamine 2 receptor antagonists for stress ulcer prophylaxis in critically ill patients: A systematic review and meta-analysis. Crit Care Med 41: 693-705, 2013.

22. Forrest JA, Finlayson ND and Shearman DJ: Endoscopy in gastrointestinal bleeding. Lancet 2: 394-397, 1974.

23. Hellmann SS, Njor SH, Lynge E, von Euler-Chelpin M, Olsen A Tjønneland A, Vejborg I and Andersen ZJ: Body mass index and participation in organized mammographic screening: A prospective cohort study. BMC Cancer 15: 294, 2015.

24. Smith LA, Gangopadhyay M and Gaya DR: Catastrophic gastrointestinal complication of systemic immunosuppression. World J Gastroenterol 21: 2542-2545, 2015.

25. Prueksapanich P, Pittayanon R, Avihingsanon $\mathrm{Y}$ and Rerknimitr R: Persistent duodenal ulcers bleeding in postkidney transplant patient treated by infliximab. BMJ Case Rep 2013: bcr2013009025, 2013.

26. Smith AD, Bai D, Marroquin CE, Tuttle-Newhall JE, Desai DM, Collins BH, Muir A, Kuo PC, McHutchison J and Rockey DC: Gastrointestinal hemorrhage due to complicated gastroduodenal ulcer disease in liver transplant patients taking sirolimus. Clin Transplant 19: 250-254, 2005

27. Cho SK, Sung YK, Choi CB and Bae SC: Impact of comorbidities on TNF inhibitor persistence in rheumatoid arthritis patients: An analysis of Korean national health insurance claims data. Rheumatol Int 32: 3851-3856, 2012.
28. Ahsberg K, Höglund P, Kim WH and von Holstein CS: Impact of aspirin, NSAIDs, warfarin, corticosteroids and SSRIs on the site and outcome of non-variceal upper and lower gastrointestinal bleeding. Scand J Gastroenterol 45: 1404-1415, 2010.

29. Narum S, Westergren T and Klemp M: Corticosteroids and risk of gastrointestinal bleeding: A systematic review and meta-analysis. BMJ Open 4: e004587, 2014.

30. Lau JY, Barkun A, Fan DM, Kuipers EJ, Yang YS and Chan FK: Challenges in the management of acute peptic ulcer bleeding. Lancet 381: 2033-2043, 2013.

31. Trawick EP and Yachimski PS: Management of non-variceal upper gastrointestinal tract hemorrhage: Controversies and areas of uncertainty. World J Gastroenterol 18: 1159-1165, 2012.

32. Mo C, Sun G, Wang YZ, Lu ML and Yang YS: PPI versus histamine $\mathrm{H} 2$ receptor antagonists for prevention of upper gastrointestinal injury associated with low-dose aspirin: Systematic review and meta-analysis. PLoS One 10: e0131558, 2015.

33. Zullo A, Hassan C, Campo SM and Morini S: Bleeding peptic ulcer in the elderly: Risk factors and prevention strategies. Drugs Aging 24: 815-828, 2007.

34. Marlicz W, Loniewski I, Grimes DS and Quigley EM: Nonsteroidal anti-inflammatory drugs, proton pump inhibitors and gastrointestinal injury: Contrasting interactions in the stomach and small intestine. Mayo Clin Proc 89: 1699-1709, 2014.

35. Ament PW, Dicola DB and James ME: Reducing adverse effects of proton pump inhibitors. Am Fam Physician 86: 66-70, 2012.

36. Shin S: Evaluation of costs accrued through inadvertent continuation of hospital-initiated proton pump inhibitor therapy for stress ulcer prophylaxis beyond hospital discharge: A retrospective chart review. Ther Clin Risk Manag 11: 649-657, 2015. 